\title{
Melanocytic Matricoma: An Additional Case with Literature Review over this Rare Entity
}

\author{
Raghda Saeed Al Maashari $^{1^{*}}$, Mowafak M Hamodat ${ }^{2}$
}

\begin{abstract}
${ }^{1}$ Dermatology specialist, Dermatology department - Sheikh Khalifa medical city (SKMC), Abu Dhabi, U.A.E
${ }^{2}$ Consultant dermatopathologist, Pathology and laboratory medicine department - Sheikh Khalifa medical city (SKMC), Abu Dhabi, U.A.E
\end{abstract}

*Corresponding author: Raghda Saeed Al Maashari, Dermatology specialist, Dermatology department - Sheikh Khalifa Medical City (SKMC), Al Bahiyabahr, House no: 15.P.o box: 7842, Abu Dhabi, U.A.E, Tel: 00971505999857 ;

E-mail: raalmaashari@seha.ae

\begin{abstract}
Melanocytic matricoma is a rare cutaneous adnexal tumour first described as a distinct entity in 1999 by Carlson et al. It commonly presents as a well circumscribed pigmented dermal nodule, frequently on sun-damaged skin of elderly men. Melanocytic matricoma is presumed to recapitulate the growth of anagen hairs.

A 36-year old female presented to the clinic with an 18-month history of a non-tender solitary darkly pigmented lobulated nodule on the right parietal scalp. The nodule was surgically excised. Histopathology showed a well-circumscribed nodular dermal lesion, consisting of a mixed population of basaloid, intermediate and shadow cells admixed with dendritic melanocytes. Immunohistochemical studies were negative for Ber - EP4 while positive for S100, Beta Catenin and E - Cadherin. Based on the clinical, microscopic and immunohistochemical findings, a diagnosis of melanocytic matricoma was made.

To date, there have been only 16 cases reported in the literature. We report an additional case of melanocytic matricoma with similar clinical and histopathological findings to previously described cases. To the best of our knowledge, this is the first case reported in a middle aged female in the Middle East. It's important to recognize this neoplasm as it should be considered in the differential diagnosis of tumours that present with a dual cell population of follicular and matrical differentiation. Long-term follow-up is indicated to exclude the aggressive potential of these matrical neoplasms.
\end{abstract}

\section{Received date: March 07, 2017 \\ Accepted date: July 18, 2017 \\ Published date: July 24, 2017}

Citation: Al Maashari Raghda S., et al. Melanocytic Matricoma: An Additional Case with Literature Review over this Rare Entity. (2017) Invest Dermatol Venereol Res 3(1): 108- 112.

DOI: $10.15436 / 2381-0858.17 .1394$

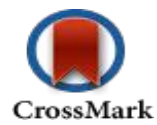

\section{Introduction}

Melanocytic matricoma is an extremely rare adnexal tumour, named owing to the content of both follicular and matrical differentiation ${ }^{[1-3]}$, first described as a distinct entity in 1999, by Carlson et al ${ }^{[4]}$. It presents as a well-circumscribed nodular proliferation typically occurring on sun-damaged skin of elderly men $^{[4-11]}$. Melanocytic matricoma is presumed to recapitulate the growth of anagen hairs ${ }^{[4]}$. The tumour is composed of a mixed population of basaloid, intermediate and shadow cells admixed with dendritic melanocytes. To date, there have been only 16 cases reported in the literature. We report an additional case of melanocytic matricoma with similar clinical and histopathological findings to previously described cases, occurring in a middle aged female from the Middle East.

\section{Case History}

A 36-year old female, previously healthy, presented to the clinic with an 18-month history of a lobulated nodule on the right parietal scalp. Initially, the lesion was asymptomatic. However, in the last few months, the nodule started to gradually grow in size and occasionally bleed upon combing.

Physical examination revealed a non-tender solitary, well circumscribed, small with a relatively broad base, darkly pigmented nodule, localized on the right parietal scalp. No family history of similar lesions. The nodule was surgically fully excised. Recurrence following excision couldn't be assessed as the patient was unavailable for follow-up review. 
Histopathology showed a well-circumscribed nodular, solid and cystic dermal lesion with no connection to the epidermis (Figure 1). It consisted mainly of peripheral palisaded basaloid cell proliferation surrounding a few solitary and clustered ghost cells. Admixed with these cells, were heavily pigmenteddendritic melanocytes. Mild nuclear atypia and few mitotic figures were noted (Figure 2). Immunohistochemical studies was negative for Ber - EP4 (Figure 3), S100 showed positive staining for the dendritic cells (Figure 4), while Beta Catenin (Figure 5) and $\mathrm{E}$ - Cadherin were both strongly and diffusely positive in the tumour cells.

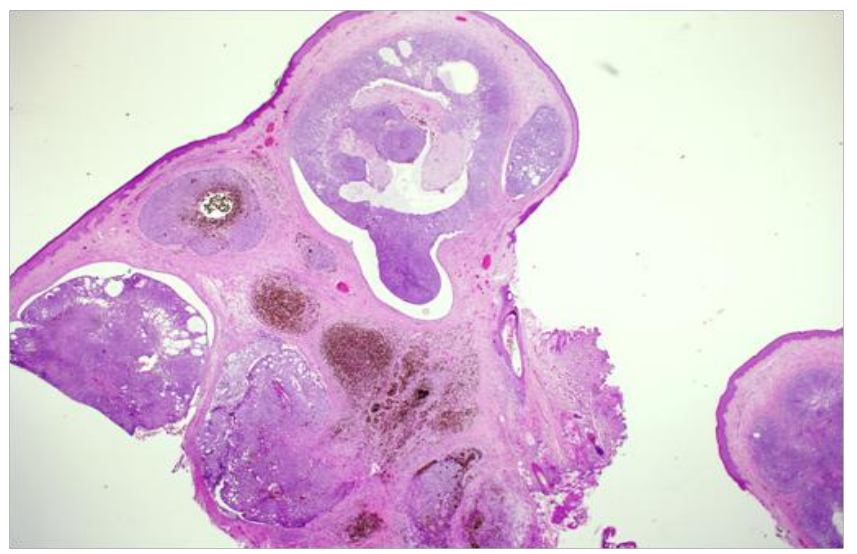

Figure 1: Well-circumscribed nodular, solid and cystic dermal lesion with no connection to the epidermis.

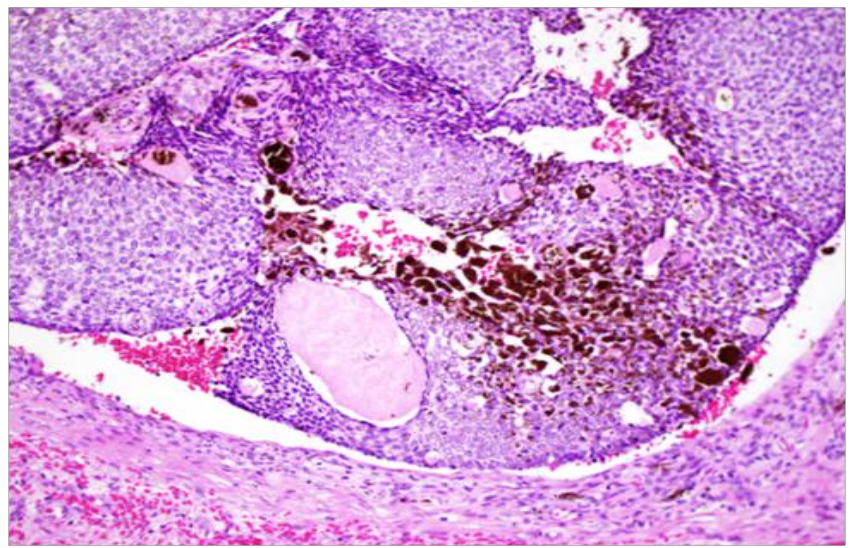

Figure 2: Consisting mainly of peripheral palisaded basaloid cell proliferation surrounding a few solitary and clustered ghost cell. Admixed with these cells, are heavily pigmented dendritic melanocytes. Mild nuclear atypia and few mitotic figures were noted.

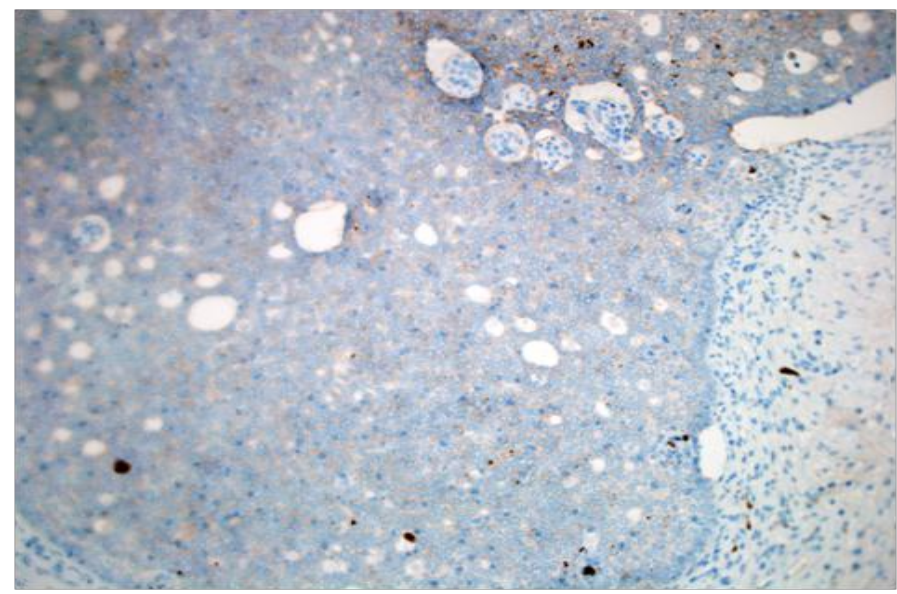

Figure 3: Immunohistochemical studies was negative for Ber - EP4.

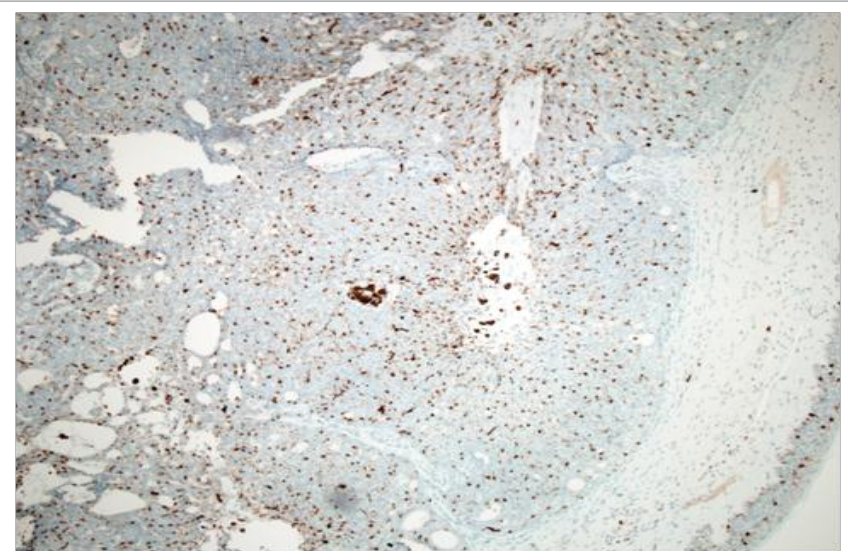

Figure 4: S100 showed positive staining for the dendritic cells.

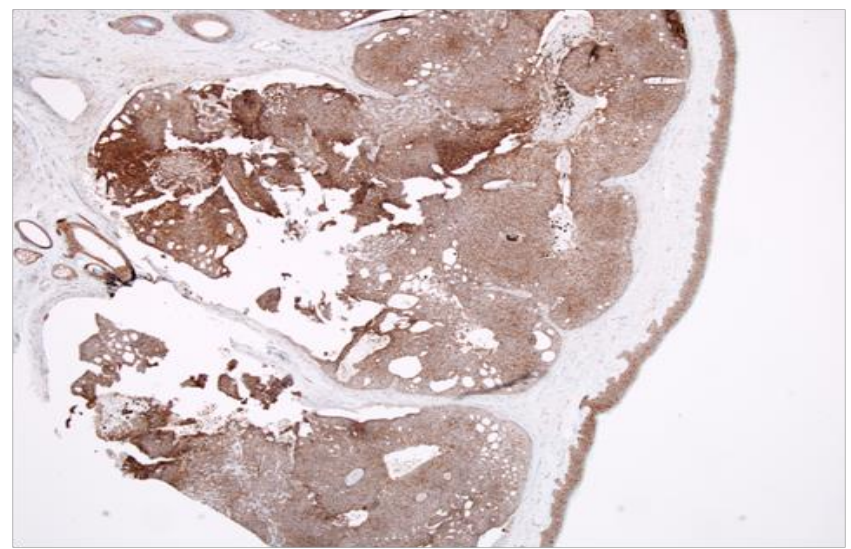

Figure 5: Beta Catenin strongly and diffusely positive in the tumour cells.

Based on the clinical, microscopic and immunohistochemical findings, a diagnosis of melanocytic matricoma was made. Our case is unique, as to the best of our knowledge; this is the first case to be reported in a middle aged female in the Middle East.

\section{Discussion}

Melanocytic matricoma is a cutaneous adnexal tumour with distinctive clinical and pathological features ${ }^{[4]}$. In 1999, Carlson et al., was the first to describe 2 cases of melanocytic matricoma as a distinct entity from pilomatricomas ${ }^{[8-14]}$, matri$\operatorname{comas}^{[2,12]}$ and pigmented matricoma variants ${ }^{[13]}$. Melanocytic matricoma presents as a well-circumscribed dermal nodule composed of matrical and supra matrical cells surrounding clustered ghosts cells and admixed pigmented dendritic melanocytes ${ }^{[4,9]}$ with no connection to the epidermis or pre-existing hair follicles and no cyst formation.

To our knowledge, only 16 cases of melanocytic matricoma have been reported to date ${ }^{[1,15]}$. Most cases described have been reported in elderly men with a history of sun-damaged $\operatorname{skin}^{[4-11]}$. Interestingly, there has been one report of a tumour with similar features to melanocytic matricoma on the tail of a $\operatorname{dog}^{[16]}$.

Normally during the anagen phase, the bulb of the hair follicle contains matrical, and supra matrical cells as well as markedly dendritic and pigmented melanocytes. And since active melanocytes are more prominent in the early anagen phase ${ }^{[17]}$, this led to the speculation that melanocytic matricoma represents an early stage of anagen follicular differentiation, in contrast to pilomatricoma, which may represent a late-stage of 
differentiation $^{[5-7,18]}$. Additionally, given the intimate interactions between epithelial cells and melanocytes during hair cycling, it has been proposed by Carlson et $a l^{[4]}$, and others, that secondary melanization is expected to occur in lesions with concomitant matrical cells. This may explain why there are frequent reports of pigmentation in other forms of neoplasms with follicular differentiation; highlighting the close interrelationship between follicular epithelium and melanocytes ${ }^{[4]}$. Moreover, since most reported cases occurred on the sun-damaged skin of elderly patients, it has been theorized that Ultraviolet Radiation (UVR) influences the migratory behavior of melanocytes, further contributing to the melanocytic colonization of melanocytic matricoma $^{[11,19]}$.

Clinically, melanocytic matricoma presents as an intensely pigmented purple to black, papule or nodule. Due to its pigmented appearance, clinical differential diagnoses that need to be considered include malignant melanoma, pigmented basal cell carcinoma, thrombosed hemangioma and porocarcinoma.

Histopathologically, melanocytic matricoma has unique pathological features. Microscopically, it presents as a well-circumscribed solid, uni-nodular, intradermal tumour characterized by a dual cell population including epithelial and melanocytic cells. The epithelial component consists of matrical and supra matrical cells surrounding 'ghost' or 'shadow' cells. The epithelial cells may display varying cytological atypia and mitotic activity. Admixed with the epithelial cells are heavily pigmented dendritic melanocytes, present in both the epithelial and the melanocytic component. Typically, this matrical neoplasm doesn't display connection to the epidermis or pre-existing hair follicles, nor cyst formation or granulomatous reaction ${ }^{[4,9]}$. Though recently, there have been a few case reports of melanocytic matricoma, described with features of epidermal connection, calcification and granulomatous respons $\mathrm{e}^{[7,10]}$.

Immunohistochemically, matrical and supra matrical cells show diffuse pattern of nuclear and cytoplasmic activity to Beta-catenin, membrane positivity to Cadherins, patchy pattern of $\mathrm{CD} 10^{[11]}$, weak expression of epithelial membrane antigen EMA $^{[11]}$ and are positive towards Pan cytokeratin ${ }^{[4,9]}$, CAM $5.2^{[4,6]}$, CK 5/6 ${ }^{[11]}$ and p63. The shadow cells show immunoreactivity to Pan cytokeratin ${ }^{[5,9,20]}, \mathrm{CK} 13^{[4]}$, and AE1/AE3 ${ }^{[7,8,20]}$ but show negative staining to both Beta-catenin and Cadherins ${ }^{[14]}$. In addition, the melanocytic component show characteristic immunohistochemical expression with S100 $\operatorname{protein}^{[4,5,9,11,20]}$, Melan $\mathrm{A}^{[6,7,9,20]}$, HMB-45 ${ }^{[4-11,18,20]}$, Vimentin ${ }^{[4,5,20]}$ and $\mathrm{E}$ cadherin $^{[9,18]}$. However, staining for Cytokeratin $7^{[11]}$, Cytokeratin $20^{[11]}$ and Ber- EP4 $4^{[4,7,11]}$ is negative. The pattern of expression of Cadherins and Beta-catenin antigen in melanocytic matricoma further supports that this rare tumour recapitulates cellular components of anagen hair bulb ${ }^{[21,22]}$.

Despite the presence of variable cytological atypia and frequent mitoses ${ }^{[5,8]}$, features that favour benign behavior of this matrical neoplasm include circumscription, small size, lack of infiltrative growth in the subcutaneous tissue and lack of lymphatic, blood vessel, perineurial and visceral invasion ${ }^{[23-31]}$. Nevertheless, in the literature there has been 5 cases $^{[32]}$ of malignant melanocytic matricoma reported, and 1 case of local recurrence ${ }^{[32]}$. Therefore, long-term follow-up is indicated to exclude aggressive behavior.

Histopathologically, the major differential diagnosis include both the pigmented and malignant variant of pilomatri- coma, matricoma, matrical carcinoma, trichoblastroma and basal cell carcinoma with matrical differentiation.

Melanocytic matricoma is both clinically and pathologically distinct from pilomatricoma. Pilomatricoma typically presents as a large, firm, cystic or solid nodule, frequently seen in young female individuals ${ }^{[1,2,33,34]}$ whereas melanocytic matricoma is frequently reported in elderly $\operatorname{men}^{[4,11]}$. Histopathological features that aids differentiation of pigmented variants of pilomatricoma from melanocytic matricoma includes the presence of multi-nodular lesions with islands of tumour cells ${ }^{[14]}$, lack of a prominent melanocytic hyperplasia ${ }^{[6]}$ and presence of calcification in more than two thirds of the case ${ }^{[1,2,33]}$ of the former as opposed to the latter which is characterized as being uni-nodular with a marked prominence of pigmented dendritic melanocytes and with the absence of calcification and granulomatous reactions $^{[4,6,9]}$.

Malignant pilomatricoma commonly presents in male adults $^{[1-3,33,34]}$, as a large ${ }^{[1-3,33,34]}$ asymmetric infiltrative tumour with occasional necrosis ${ }^{[1,2,33,34]}$. The main histopathological feature that characterizes malignant pilomatricoma is the lack of prominent melanocytic proliferation with heavy melanin pigmentation and the presence of a variable number of atypical mitoses $^{[2]}$, while the latter is absent in the non malignant melanocytic matricoma ${ }^{[14]}$.

Around $75-100 \%$ of pilomatricomas ${ }^{[35,36]}$, have activating mutations in exon 3 of CTNNB1, which encodes for beta-catenin $^{[37]}$. Based on the nuclear localization of b-catenin in basaloid cells in melanocytic matricoma, may imply that mutations of melanocytic matricoma are similar to pilomatricoma ${ }^{[38]}$. Subsequently, further studies of CTNNB1 mutations in various matricomas will be of high importance, to determine whether these rare tumours are genetically related to other tumours of the hair matrix.

Historically, there has been some debate on whether melanocytic matricoma represents a distinct entity or is simply a variant of matricoma ${ }^{[39]}$. However, these two entities are considered to be different. Matricomas, are defined as benign neoplasms containing all the cellular elements of a pilomatricoma but with a different silhouette ${ }^{[2]}$, where they are composed of many small, discrete, solid, solid cystic or cystic aggregations positioned throughout the dermis and occasionally may extend into the subcutaneous fat, in contrast to melanocytic matricoma which is uni-nodular ${ }^{[12,40]}$. Microscopic features that discriminates melanocytic matricoma from matricoma include the presence of melanocytic proliferation ${ }^{[6]}$, absence of a connection with the epidermis or adnexal epithelium and absence of a granulomatous component or calcifications in the former ${ }^{[4,9]}$. While matricomas are benign, matrical carcinoma on the other hand, tend to follow a locally aggressive behavior, where they demonstrate deep infiltration with areas of necrosis.

Furthermore, features that distinguish melanocytic matricoma from trichoblastomas with matrical differentiation is the absence of the abundant stromal component with primitive follicular bulb formation in melanocytic matricoma ${ }^{[4]}$, compared to the large size, exuberant stoma with predominance of germinative cells in trichoblastomas with matrical differentiation ${ }^{[12]}$.

Finally, one of the most important differential diagnoses to be ruled out is basal cell carcinomas with matrical differentiation, which presents as a slowly growing ulcerated nodule, commonly in elderly men. Histopathological features of basal 
cell carcinoma with matrical differentiation include infiltrative tumour aggregates, peripheral nuclear palisading, and retraction clefts $^{[12,41-47]}$. Moreover, basal cell carcinomas with matrical differentiation shows positivity towards Ber-EP4 ${ }^{[1,2,34]}$ and a focal and membranous pattern ${ }^{[44,46]}$ of staining with beta-catenin, in contrast to melanocytic matricomas, which is negative to BerEP4 $4^{[4,7,11]}$ and show an intense, pattern of nuclear and cytoplasmic positivity to beta-catenin ${ }^{[9,11,18]}$.

\section{Conclusion}

In conclusion, melanocytic matricoma is a rare cutaneous adnexal tumour commonly presenting as a well circumscribed pigmented dermal nodule, frequently on sun-damaged skin of elderly men. To the best of our knowledge, this is the first case reported in a middle aged female in the Middle East. It's important to recognize this neoplasm as it should be considered in the differential diagnosis of tumours that presents with a dual cell population of follicular and matrical differentiation. With case reports of malignant changes and local recurrence, longterm follow-up is indicated to exclude the aggressive potential of these matrical neoplasms.

\section{References}

1. McKee, P.H., Calonje, E., Granter, S.R. Pathology of the skin with clinical correlations, 3rd ed. Philadelphia: Elsevier Mosby (2005).

Pubmed | Crossref $\mid$ Others

2. Weedon, D., Strutton, G., Rubin, A.I. Weedon D. Weedon's skin pathology, 3rd ed. Oxford: Churchill Livingstone, 2010. (2012) Dermatol Pract Conc 2(1): 79-82.

Pubmed | Crossref | Others

3. Kazakov, D.V., Michal, M., Kacerovska, D. Lesions with predominant follicular differentiation. In Kazakov DV, Michal M, Kacerovska D, eds. Cutaneous adnexal tumors. (2012) Philadelphia: Lippincott Williams \& Wilkins 173. 36

Pubmed $\mid$ Crossref $\mid$ Others

4. Carlson, J.A., Healy, K., Slominski, A., et al. Melanocytic matricoma: a report of two cases of a new entity. (1999) Am J Dermatopathol 21(4): 344-349.

Pubmed | Crossref $\mid$ Others

5. Williams, C.M., Bozner. P., Oliveri, C.V., et al. Melanocytic matricoma: case confirmation of a recently described entity. (2003) J Cutan Pathol 30(4): 275-278.

Pubmed | Crossref | Others

6. Horenstein, M.G., Kahn, A.G. Pathologic quiz case: a 69-year-old man with a brown-black facial papule. Melanocytic matricoma. (2004) Arch Pathol Lab Med 128(11): e163-164.

Pubmed | Crossref | Others

7. Islam, M.N., Bhattacharyya, I., Proper, S.A., et al. Melanocytic matricoma: a distinctive clinicopathologic entity. (2007) Dermatol Surg 33(7): 857-863.

Pubmed | Crossref | Others

8. Monteagudo, B., Requena, L., Used-Aznar, M.M., et al. Melanocytic matri- coma. (2008) Actas Dermosifiliogr 99(77): 576-578.

Pubmed $\mid$ Crossref $\mid$ Others

9. Cartaginese, F., Sidoni, A. Melanocytic matricoma. Report of a further case with clinicopathological and immunohistochemical findings, differential diagnosis and review of the literature. (2010) Histol Histopathol 25(6): 713-717.

Pubmed | Crossref $\mid$ Others

10. Tallon, B., Cerroni, L. Where pigmented pilomatricoma and melanocytic matricoma collide. (2010) Am J Dermatopathol 32(8): 769-773. Pubmed | Crossref | Others

11. Zussman, J., Sheth, S., Ra, S.H., et al. Melanocytic matricoma with melanocytic atypia: report of a unique case and review of the literature. (2011) Am J Dermatopathol 33(5): 508-512.

Pubmed | Crossref $\mid$ Others

12. Ackerman, A.B., De Viragh, P.A., Chongchtnant, N. Pilomatricoma and matricoma. In Spahr JF Jr. Neoplasms with follicular differentiation. (1993) Philadelphia: Lea and Febiger 477.

Pubmed $\mid$ Crossref $\mid$ Others

13. Spitz, D., Fisher, D., Friedman, R.J., et al. Pigmented pilomatricoma. A clinical simulator of malignant melanoma. (1981) J Dermatol Surg Oncol 7(11): 903-906.

Pubmed | Crossref | Others

14. Tanboon, J., Manonukul, J., Pattanaprichakul, P. Melanocytic matricoma: two cases of a rare entity in women. (2014) J Cutan Pathol 41(10): 775-782.

Pubmed | Crossref | Others

15. Barrado-Solis, N., Moles-Poveda, P., Roca-Estelles, M.J., et al. Melanocytic matricoma with melanocytic atypia: report of a new case. (2016) J Eur Acad Dermatol Venereol 30(5): 859-860.

Pubmed | Crossref $\mid$ Others

16. Saito, S., Suzuki, K., Shibuya, H., et al. Melanocytic matricoma in a dog. (2005) Vet Pathol 42(4): 499-502.

Pubmed | Crossref | Others 
17. Slominski, A., Paus, R. Melanogenesis is coupled to murine anagen: toward new concepts for the role of melanocytes and the regulation of melanogenesis in hair growth. (1993) J Invest Dermatol 101(1 Suppl): S90- S97.

Pubmed | Crossref | Others

18. Soler, A.P., Burchette, J.L., Bellet, J.S., et al. Cell adhesion protein expression in melanocytic matricoma. (2007) J Cutan Pathol 34(6): 456-460.

Pubmed | Crossref | Others

19. Walker, G.J., Kimlin, M.G., Hacker, E., et al. Murine neonatal melanocytes exhibit a heightened proliferative response to ultraviolet radiation and migrate to the epidermal basal layer. (2009) J Invest Dermatol 129(1): 184-193.

Pubmed | Crossref | Others

20. Rizzardi, C., Brollo, A., Colonna, A., et al. A tumor with composite pilofolliculosebaceous differentiation harboring a recently described new entity-melanocytic matricoma. (2002) Am J Dermatopathol 24(6): 493-497.

Pubmed | Crossref | Others

21. Müller-Röver, S., Tokura, Y., Welker, P., et al. E- and P-cadherin expression during murine hair follicle morphogenesis and cycling. (1999) Exp Dermatol 8(4): 237-246.

Pubmed | Crossref | Others

22. Moreno-Bueno, G., Gamallo, C., Pérez-Gallego, L., et al. beta-catenin expression in piloma- trixomas. Relationship with beta-catenin gene mutations and comparison with beta-catenin expression in normal hair follicles. (2001) Br J Dermatol 145(4): 576-581.

Pubmed | Crossref $\mid$ Others

23. Hardisson, D., Linares, M.D., Cuevas-Santos, J., et al. Pilomatrix carcinoma: a clinicopathologic study of six new cases and review of the literature. (2001) Am J Dermatopathol 23(5): 394-401.

Pubmed | Crossref $\mid$ Others

24. Lopansri, R., Mihm, M.C. Pilomatrix carcinoma or calcifying epithelioma of Malherbe: a case report and review of the literature. (1980) Cancer 45(9): 2368-2373.

Pubmed | Crossref | Others

25. Weedon, D., Bell, J., Maize, J. Matrical carcinoma of the skin (1980) J Cutan Pathol 7(1): 39-42.

Pubmed | Crossref | Others

26. Wood, M.G., Parhizgar, B., Beerman, H. Malignant pilomatricoma (1984) Arch Dermatol 120(6): 770-773.

Pubmed | Crossref | Others

27. Van der Walt, J.D., Rohlova, B. Carcinomatous transformation in a pilomatrixoma. (1984) Am J Dermatopathol 6(1): 63-69.

Pubmed | Crossref $\mid$ Others

28. Chen, K.T.K., Taylor, D.R. Jr. Pilomatrix carcinoma. (1986) J Surg Oncol 33(2): 112-114.

Pubmed | Crossref | Others

29. Green, D.E., Sanusi, I.D., Fowler, M.R. Pilomatrix carcinoma. (1987) J Am Acad Dermatol 17(2 pt 1): 264-270.

Pubmed | Crossref | Others

30. Sau, P., Lupton, G.P., Graham, J.H. Pilomatrix carcinoma. (1993) Cancer 71(8): 2491-2498.

Pubmed | Crossref | Others

31. Niedermeyer, H.P., Peris, K., Hofler, H. Pilomatrix carcinoma with multiple visceral metastases. Report of a case. (1996) Cancer 77(7): 1311-1314.

Pubmed | Crossref | Others
32. Ardakani, N.M., Palmer, D.L., Wood, B.A. Malignant Melanocytic Matricoma: A Report of 2 Cases and Review of the Literature. (2016) Am J Dermatopathol 38(1): 33-38.

Pubmed | Crossref $\mid$ Others

33. Lever, W.F., Elder, D.E. Lever's histopathology of the skin. Philadelphia: Lippincott Williams and Wilkins. $10^{\text {th }}$ edition (2009).

Pubmed $\mid$ Crossref $\mid$ Others

34. LeBoit, P.E., Burg, G., Weedon, D., et al. World Health Organization classification of tumours. Pathology and genetics of skin tumours. (2006) Lyon: IARC Press.

Pubmed $\mid$ Crossref $\mid$ Others

35. Chan, E.F., Gat, U., McNiff, J.M., et al. A common human skin tumour is caused by activating mutations in beta-catenin. (1999) Nat Genet 21(4): 410-413.

Pubmed | Crossref | Others

36. Kajino, Y., Yamaguchi, A., Hashimoto, N., et al. Beta-catenin gene mutation in human hair follicle-related tumors. (2001) Pathol Int 51(7): 543-548.

Pubmed $\mid$ Crossref $\mid$ Others

37. Lazar, A.J., Calonje, E., Grayson, W., et al. Pilomatrix carcinomas contain mutations in CTNNB1, the gene encoding $\beta$-catenin. (2005) J Cutan Pathol 32(2): 148-157.

Pubmed | Crossref | Others

38. Nikaido, M., Yamada, M., Konno, T., et al. Agminated pigmented matricoma: a case of a unique tumor with a multifocal appearance composed of neoplastic matrical cells with a significant component of melanocyte. (2013) J Cutan Pathol 40(9): 823-828.

Pubmed | Crossref | Others

39. Resnik, K.S. Is melanocytic matricoma a bona fide entity or is it just one type of matricoma? (2003) Am J Dermatopathol 25(2): 166-167.

Pubmed | Crossref | Others

40. Carlson, J.A., Slominski, A., Mihm, M.C. What are the clinichopathologic features of matricoma? (2003) Am J Dermatopathol 25(5): 446-447.

Pubmed | Crossref | Others

41. Aloi, F.G., Molinero, A., Pippione, M. Basal cell carcinoma with matrical differentiation. Matrical carcinoma. (1988) Am J Dermatopathol 10(6): 509-513.

Pubmed | Crossref $\mid$ Others

42. Ambrojo, P., Aguilar, A., Simón, P., et al. Basal cell carcinoma with matrical differentiation. (1992) Am J Dermatopathol 14(4): 293-297.

Pubmed | Crossref $\mid$ Others

43. Kim, S.H., Lee, M.G., Lee, K.G. Basal cell carcinoma with matrical differentiation. (2003) Yonsei Med J 44(3): 523-525.

Pubmed | Crossref | Others

44. Haskell, H.D., Haynes, H.A., McKee, P.H., et al. Basal cell carcinoma with matrical differentiation: a case study with analysis of beta-catenin. (2005) J Cutan Pathol 32(3): 245-250.

Pubmed $\mid$ Crossref $\mid$ Others

45. Ali, F., Brown, A., Gottwald, L., et al. Basal cell carcinoma with matrical differentiation in a transplant patient: a case report and review of the literature. (2005) J Cutan Pathol 32(6): 445-448.

Pubmed | Crossref | Others

46. Del Sordo, R., Cavaliere, A., Sidoni, A. Basal cell carcinoma with matrical differentiation: expression of beta-catenin [corrected] and osteopontin. (2007) Am J Dermatopathol 29(5): 470-474.

Pubmed $\mid$ Crossref $\mid$ Others

47. Murphy, M., Elaba, Z. Basal cell carcinoma with matrical differentiation. (2011) Int J Dermatol 50(4): 487-488.

Pubmed $\mid$ Crossref $\mid$ Others
Online ISSN: $2381-0858$

Journal Title: Investigative Dermatology and Venereology Research Journal Short Name: Invest Dermatol Venereol Res
Ommega Online Publishers

E-mail: editor.dermatology@ommegaonline.org

Website: www.ommegaonline.org 